\title{
Antibody-Based Therapies in Multiple Myeloma
}

\author{
Yu-Tzu Tai and Kenneth C. Anderson \\ Department of Medical Oncology, Jerome Lipper Multiple Myeloma Center, Dana-Farber Cancer Institute, Harvard Medical School, \\ 44 Binney Street, Boston, MA 02115, USA \\ Correspondence should be addressed to Yu-Tzu Tai, yu-tzu_tai@dfci.harvard.edu
}

Received 18 October 2010; Accepted 4 January 2011

Academic Editor: Ignazio Majolino

Copyright ( $) 2011$ Y.-T. Tai and K. C. Anderson. This is an open access article distributed under the Creative Commons Attribution License, which permits unrestricted use, distribution, and reproduction in any medium, provided the original work is properly cited.

\begin{abstract}
The unmet need for improved multiple myeloma (MM) therapy has stimulated clinical development of monoclonal antibodies (mAbs) targeting either MM cells or cells of the bone marrow (BM) microenvironment. In contrast to small-molecule inhibitors, therapeutic mAbs present the potential to specifically target tumor cells and directly induce an immune response to lyse tumor cells. Unique immune-effector mechanisms are only triggered by therapeutic mAbs but not by small molecule targeting agents. Although therapeutic murine mAbs or chimeric mAbs can cause immunogenicity, the advancement of genetic recombination for humanizing rodent $\mathrm{mAbs}$ has allowed large-scale production and designation of mAbs with better affinities, efficient selection, decreasing immunogenicity, and improved effector functions. These advancements of antibody engineering technologies have largely overcome the critical obstacle of antibody immunogenicity and enabled the development and subsequent Food and Drug Administration (FDA) approval of therapeutic Abs for cancer and other diseases.
\end{abstract}

\section{Introduction}

Despite the landmark approval of the anti-CD20 mAb rituximab for the treatment of B-cell malignancies, to date, no mAb-based therapy has been approved for MM treatment. The development of effective cytotoxic mAb therapies in MM has been hindered by the lack of uniquely and constitutively expressed target molecules on all MM cells. Indeed, studies in early 2000 demonstrated only minimal activity of anti-CD20 rituximab and antibodies against plasma cell-specific CD38 antibodies in MM [1-4]. However, numerous efforts to identify new targets on MM cells including gene expression profiling and oncogenomic studies are under way. Derived mAbs (e.g., against CD40, HM1.24, IGF-1R, CD56, CS1, CD138, CD74, IL-6R, CD38, TRAIL-R1, and the activin receptor type IIA (ActRIIA)) have already demonstrated promising preclinical as well as early clinical activity (Table 1).

Given the importance of the bone marrow (BM) microenvironment for MM cell growth, survival, and drug resistance, $\mathrm{mAbs}$ have been additionally designed to functionally block both autocrine and paracrine secreted cytokines and growth factors as well as molecules mediating MM-stromal cell interaction. For example, mAbs targeting interleukin-6 (IL-6), vascular endothelial growth factor (VEGF), Receptor Activator of NFkB ligand (RANKL) (also known as osteoprotegerin ligand (OPGL)), and Dickkopf homolog 1 (DKK1) are among those under clinical evaluation. Specifically, targeting bone-MM cell interactions via bone biology modulating factors such as DKK1 and RANKL is likely to trigger anti-MM effects but also improves bone disease thereby improving both patient survival as well as patient's quality of life.

In the coming years, the preclinical progress in defining novel MM markers will be continued and subsequently will advance the clinical development of therapeutic mAbs, alone or in combination with other anti-MM agents, to improve patient outcome in MM.

\section{Mechanisms of Action of Therapeutic Monoclonal Antibodies}

Antibodies of IgG, the most commonly used immunoglobulin form in cancer therapy, are unique proteins with dual functionality. Therapeutic mAbs use one or more following mechanisms (Figure 1) to reduce tumor burden in patients. 


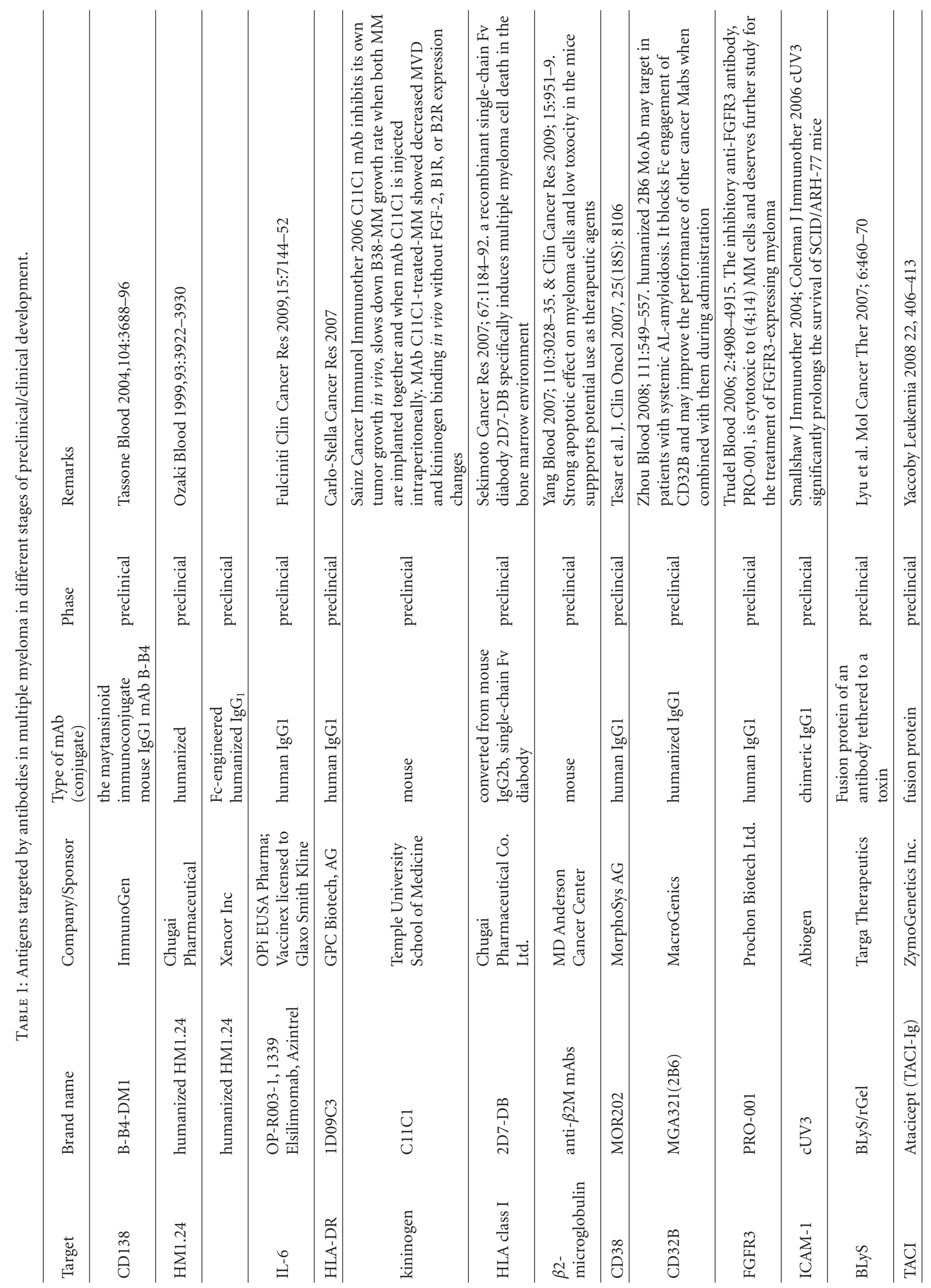




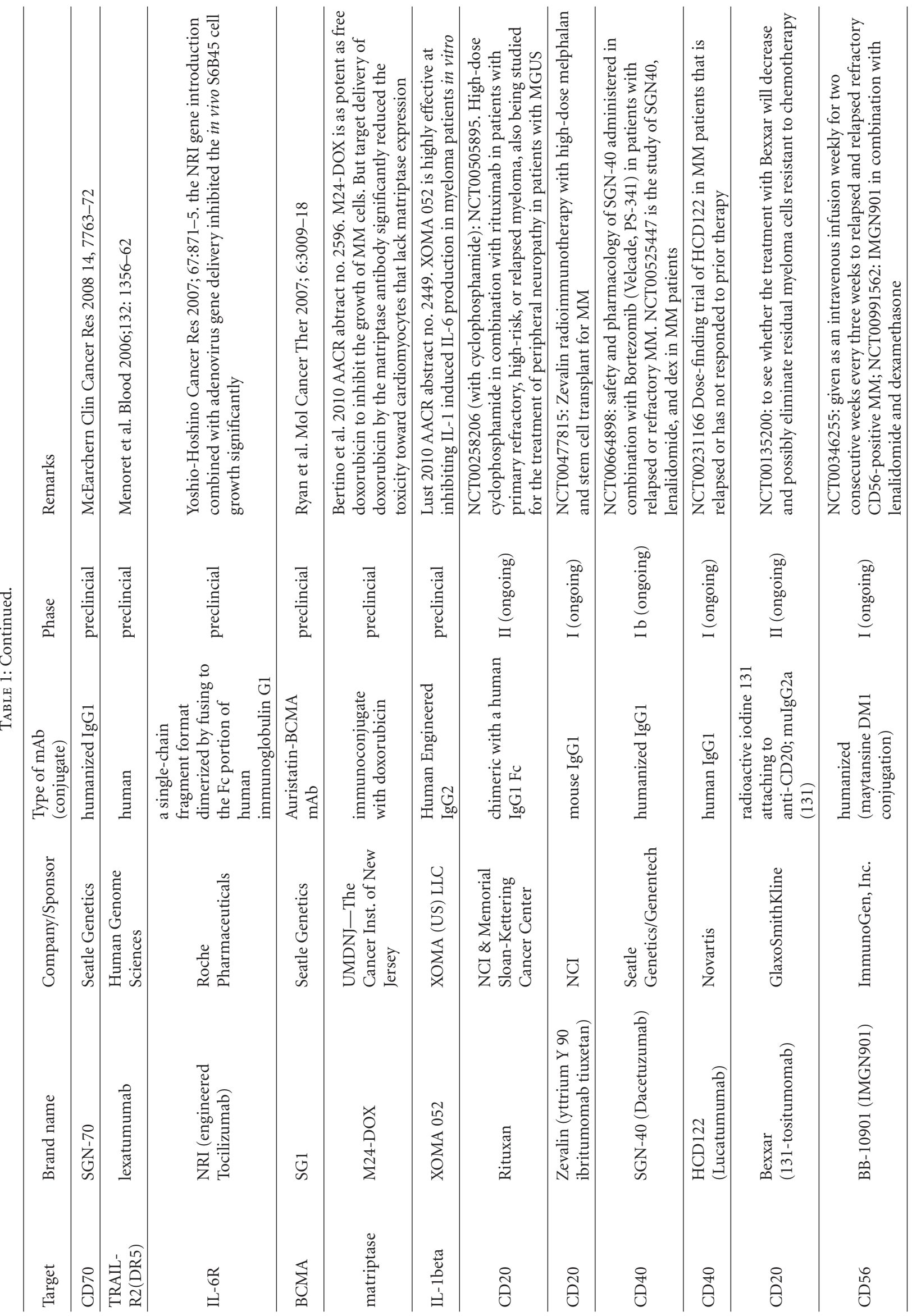




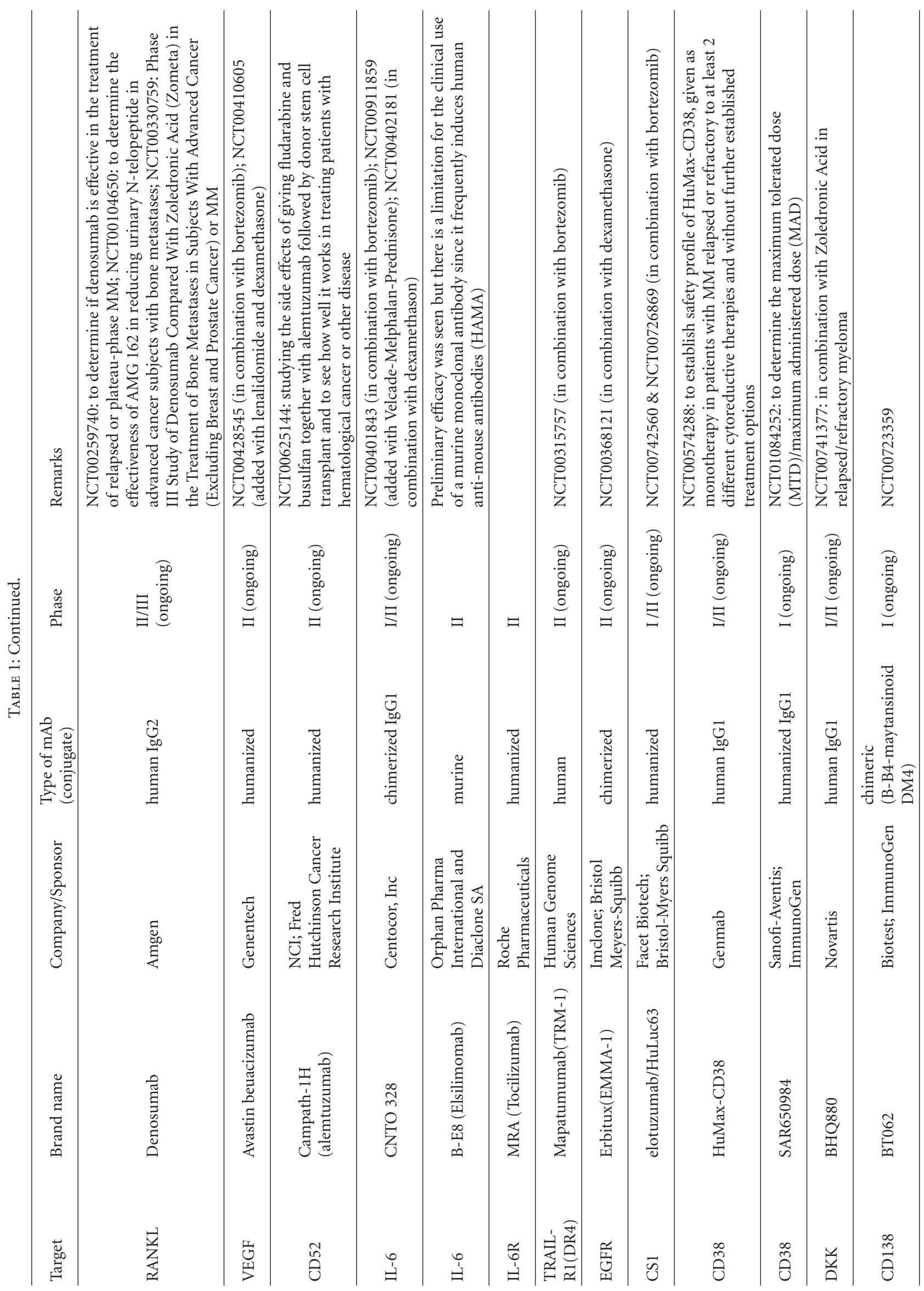




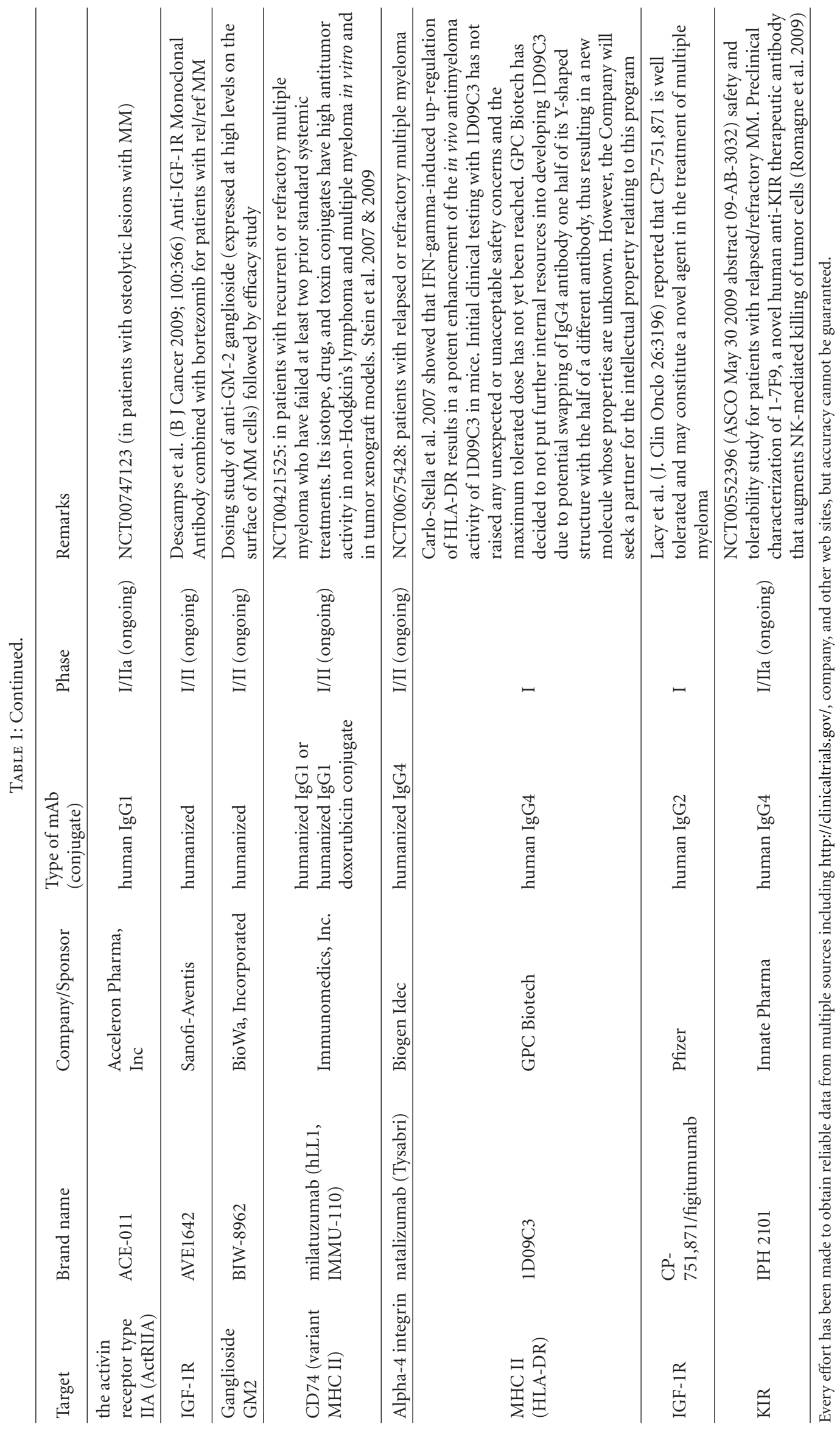




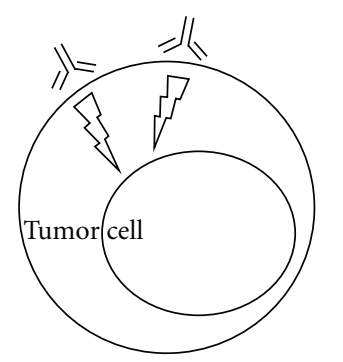

Apoptosis or growth arrest via

1. Blockade of receptorligand interaction

2. Activation of apoptotic signaling pathways

3. Specific targeting and delivering immunotoxins

(a)

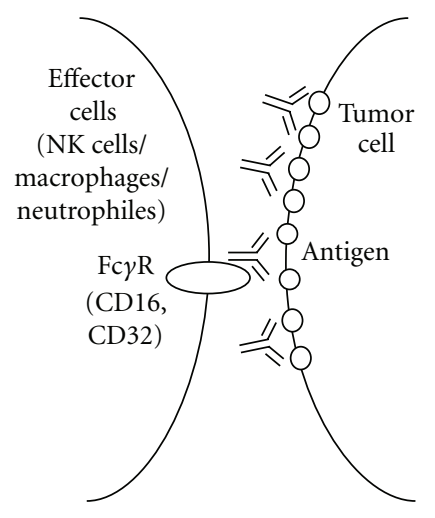

ADCC

(b)

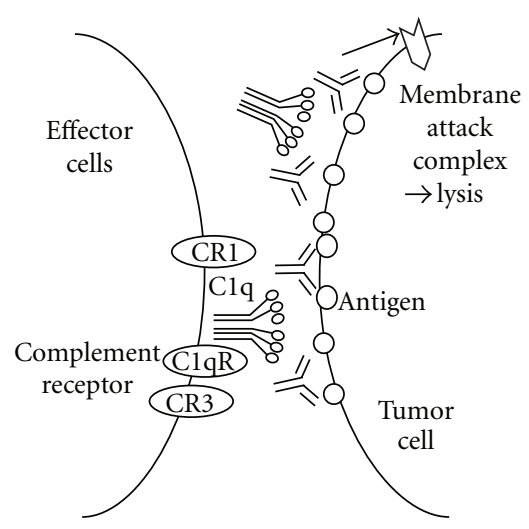

CDC

(c)

FIgURE 1: Mechanisms of actions associated with therapeutic monoclonal antibodies. (a) Therapeutic antibodies could directly induce apoptosis or growth arrest upon binding to cell surface antigen on tumor cells. Rituximab and Mapatumumab (anti-TRAIL-R1) could induce growth inhibition or apoptosis signaling to directly block tumor cell growth and survival. Such mechanism of action was employed by mAbs conjugated with toxins, that is, maytansinoids (DM1, DM4) for BB-10901 (anti-CD56) and BT062 (anti-CD138), thus directly target and eliminate tumor cells. Most of the approved therapeutic mAbs belong to IgG1 subclass, which has a long half-life and trigger potent immune-effector functions. (b) Following the binding of mAbs to a specific target on a tumor cells, antibody-dependent cellular cytotoxicity (ADCC) is triggered by interactions between the Fc region of an antibody bound to a tumor cell and Fc receptors, particularly FcRI and FcRIII, on immune effector cells such as neutrophils, macrophages, and natural killer cells. MAb-coated tumor cells are phagocytosed by macrophages or undergo cytolysis by NK cells. (c) In the case of complement-dependent cytotoxicity (CDC), recruitment of C1q by IgG bound to the tumor cell surface is an obligatory first step. This triggers a proteolytic cascade that leads to generation of the effector molecule, $\mathrm{C} 3 \mathrm{~b}$, and then to formation of a membrane attack complex that kills the target cell by disrupting its cell membrane.

They can be categorized into direct and indirect actions. Three modes of action could be further subcategorized from the direct action (Figure 1(a)) of mAb-based cancer therapy, including blocking the function of target signaling molecules or receptors, stimulating apoptosis signaling cascades, and targeting function to selectively target tumor cells and deliver toxins. The receptor functional blocking can occur by inhibiting ligand binding to inhibit cell cycle progression, DNA repair, or angiogenesis. It could also occur by increasing internalization of receptors or decreasing proteolytic cleavage of receptors. In the case of targeting function, mAbs could be conjugated with immunotoxins, that is, antitubulin agents (DM1/DM4, auristatin), doxorubicin, radioisotopes, or other chemotherapeutic drugs, thus selectively targeting and killing tumor cells. Indirect action of mAb therapy is mediated by the immune system. The elimination of tumor cells using mAbs depends on Ig-mediated mechanisms, including antibody-dependent cellular cytotoxicity (ADCC) and complement-dependent cytotoxicity (CDC), to activate immune effector cells to lyse target tumor cells (Figure 1(b)) These two mechanisms are believed to have the greatest impact, although there are conflicting views of which of these two pathways contributes the most to the response. ADCC involves the recognition of the Ab by immune cells that engage the Ab-marked cells and either through their direct action, or through the recruitment of other cell types, led to the tagged-cell's death. CDC (Figure 1(c)) is a process where a cascade of different complement proteins become activated, usually when several IgGs are in close proximity to each other, either with one direct outcome being cell lysis, or one indirect outcome being attracting other immune cells to this location for effector cell function.

\section{Antibodies Targeting Cell Surface Protein on MM Cells}

Several mAbs directed against MM cell surface are being investigated as potential therapy in MM. Listed below are mAbs against receptor antigens that are currently under clinical development or investigation in MM.

\subsection{Limited Clinical Benefit from Anti-CD20 mAb Rituximab in $M M$. MM is usually not considered as a disease suitable for anti-CD20 therapy due to weak CD20 expression in the majority of patients. For example, results from a clinical phase II trial in relapsed MM showed that Rituximab treatment yielded significant reductions in circulating B cells and serum IgM levels but had no beneficial clinical effect [5]. \\ Moreover, rituximab was investigated for maintenance therapy in MM following autologous hematopoietic stem cell transplantation (SCT) [2]. Although the number of MM patients was too low to draw definitive conclusions, the use of rituximab in this setting was associated with an unexpectedly}


high rate of early relapse. The authors therefore hypothesized a possible role for rituximab in provoking a further decrease in the residual, normal B-cell activity within the context of the complex network of antitumor immune response. Taken together, the resistance of MM cells against rituximab could be due to the level of CD20 expression, dissociated action of CDC and ADCC, polymorphism in FGCR3 (CD16) receptor, and an inadequate dose schedule.

In contrast, other studies demonstrated that the CD20+ phenotype is associated with patients with $\mathrm{t}(11,14)$ (q13;q32) and with shorter survival [6] and that occasional clinical responses have been achieved in selected patients with $\mathrm{CD} 20^{+}$myelomatous plasma cells $[7,8]$.

Finally, new insights suggest that circulating $\mathrm{CD} 20^{+}$ clonotypic B cells act as precursors or "neoplastic stem cells" in MM patients, representing the proliferative compartment of the disease able to play a role in determining relapse after effective treatments [9]. Thus, clinical trials using rituximab in MM may deserve further investigation.

3.2. Monoclonal Antibodies Targeting IL-6R to Overt IL6/IL-6R Function. IL-6 is a major growth and survival factor in MM cells whose effects are mainly paracrine [10]. Various therapeutic agents which affect IL-6-mediated effects have been tested including IL-6-conjugated mAbs directed against IL-6R and IL-6 [11]. IL-6R antagonist SANT-7, in combination with Dex and all-transretinoic acid (ATRA) or zoledronic acid, strongly inhibited growth and induced apoptosis in MM cells [12-14]. These studies suggest that overcoming IL-6-mediated cell resistance by SANT-7 potentiates the effect of glucocorticoides and bisphosphonates on MM cell growth and survival, providing a rationale for therapies using IL-6 antagonists in MM.

Tocilizumab (MRA, atlizumab, Roche Pharmaceuticals) is a humanized anti-human IL-6R mAb (rhPM-1, IgG1 class) designed by using genetic engineering technology and the first therapeutic mAb developed in Japan [15]. Tocilizumab specifically blocks IL-6 actions and ameliorates diseases associated with IL-6 overproduction [16]. For example, besides Castleman's disease and rheumatoid arthritis (RA), tocilizumab has been shown to be effective in patients with juvenile idiopathic arthritis and Crohn's disease [17, 18]. Tocilizumab treatment is generally well tolerated and safe. Moreover, blockade of IL-6R may prove effective in limiting MM cell growth. Indeed it is now evaluated in open-label Phase I (USA) and II (France) trials to assess its safety and efficacy as monotherapy in MM patients who are not candidates for, or who have relapsed after stem cell transplantation (SCT).

In addition, NRI, another receptor inhibitor of IL-6 genetically engineered from tocilizumab, is under preclinical evaluation [19]. NRI consists of VH and VL of tocilizumab in a single-chain fragment format dimerized by fusing to the Fc portion of human immunoglobulin G1. The binding activity to IL-6R and the biological activity of the purified NRI were found to be similar to those of parental tocilizumab. Because NRI is encoded on a single gene, it is easily applicable to a gene delivery system using virus vehicles. An adenovirus vector encoding NRI was administered to mice intraperitoneally (i.p.) and monitored for the serum NRI level and growth reduction property on the xenografted IL-6dependent MM cell line S6B45. These findings indicate that NRI is a promising agent applicable to the therapeutic gene delivery approach for IL-6-driven diseases.

3.3. Targeting CD40 by SGN-40 or HCD122. Novel monoclonal antibodies targeting CD40 activation in MM cells, SGN-40/Dacetuzumab (Seattle Genetics, Genentech) and HCD122/Lucatumumab (Novartis), have been investigated $[20,21]$. In preclinical studies, SGN-40, a humanized IgG partial agonistic mAb mediates cytotoxicity against CD40expressing MM cell lines and patient MM cells via suppression of IL-6-induced proliferative and antiapoptotic effects, as well as ADCC [20]. SGN-40 also induced significant antitumor activity in xenograft mouse models of human MM and lymphoma [22]. HCD122 (CHIR12.12) (Novartis), a novel, fully human, $\operatorname{IgG}_{1}$ antagonistic $\mathrm{mAb}$ specifically blocked CD40L-induced adhesion, cytokine secretion, and survival of MM, as well as induced marked ADCC against CD40+ MM cells [21]. In vivo anti-MM activity by HCD122 was demonstrated in a xenograft model of 12BM MM plasmacytoma in mice [23]. Early clinical trials have evaluated the pharmacokinetics, safety, and efficacy of dacetuzumab monotherapy in patients with relapsed/refractory MM and other B-cell tumors $[24,25]$. Phase I data suggest both agents are well tolerated with no immunogenicity and show early evidence of single-agent clinical activity in relapsed and refractory MM and NHL [26, 27]. SGN-40 Phase Ib clinical trials in combination with lenalidomide and dexamethasone/or bortezomib are planned based on enhanced antiMM activities when combining SGN-40 with lenalidomide [28].

3.4. Targeting CS1 by HuLuc63/Elotuzumab in MM. Using subtractive hybridization of naïve B-cell cDNA from memory B/plasma cell cDNA, CS1 (CD2 subset-1, CRACC, SLAMF7, CD319), a novel member of the signaling lymphocyte activating molecule- (SLAM-) related receptor family, was identified to be highly expressed in plasma cells [29, 30]. Specifically, CS1 mRNA and protein are expressed in CD138-purified primary tumor cells from the majority of MM patients (>97\%), but neither in major body organs nor CD34+ stem cells. To a low extent, its expression was also observed in NK cells, a subset of $\mathrm{T}$ cells, activated monocytes and activated dendritic cells. CS1 may contribute to MM pathogenesis by increasing MM cell adhesion, clonogenic growth, and tumorigenicity via c-maf-mediated interactions with BMSCs [31]. A novel humanized antiCS1 mAb HuLuc63 (elotuzumab) was selected for clinical development due to its potent tumor-killing activity in vivo and in vitro. Specifically, elotuzumab induced significant ADCC against MM cells even in the presence of BMSCs. Moreover, it triggered autologous ADCC against primary MM cells resistant to conventional or novel therapies including bortezomib and HSP90 inhibitor, and markedly 
enhanced HuLuc63-induced MM cell lysis when pretreated with conventional or novel anti-MM drugs $[29,32]$.

A phase I study of HuLuc63 was well tolerated in MM patients [33]. Preliminary PK data reveal that peak serum drug levels for the $0.5 \mathrm{mg} / \mathrm{kg}$ dosing cohort reached 10 $\mathrm{mg} / \mathrm{mL}$, which was sufficient to achieve CS1 saturation of at least $70 \%$ on the antigen rich NK cell subset. Drug levels dropped below $1 \mathrm{mg} / \mathrm{mL}$ by day 7 , however, coinciding with a decrease in saturation. This indicates that the higher doses to be used in subsequent cohorts may achieve and surpass sustained concentrations in patients above this level. Enrollment is continuing to determine the MTD. Early results of clinical trials of HuLuc63 in combination with bortezomib or lenalidomide or dexamethasone were reported at the ASH meeting 2009 [34, 35], suggesting that elotuzumab may enhance the activity of bortezomib and lenalidomide in treating MM with acceptable toxicity. PK analysis suggests a serum half-life of 10-11 days at higher doses (10 and $20 \mathrm{mg} / \mathrm{kg}$ ). Preliminary analysis of mononuclear cells of peripheral blood and the BM indicates that objective responses correlate well with complete saturation of CS1 sites by elotuzumab on BM plasma cells and NK cells. The combination of elotuzumab with lenalidomide and lowdose dexamethasone has a manageable adverse event profile and compared to historical data for lenalidomide and highdose dexamethasone, the preliminary efficacy data (PR of $92 \%$ ) are very encouraging.

\subsection{Targeting CD56 with Immunotoxin-Conjugated mAb.} HuN901 conjugated with the maytansinoid $\mathrm{N}^{2^{\prime}}$-deacetyl$\mathrm{N}^{2^{\prime}}$-(3-mercapto-1-oxopropyl)-maytansine (DM1), a potent antimicrotubular cytotoxic agent may provide targeted delivery of the drug to CD56-expressing tumors including MM. HuN901-DM1 has significant in vitro and in vivo anti-MM activity at doses that were well tolerated in a murine model [36].

The phase I clinical study of huN901-DM1 (BB-10901) in $23 \mathrm{MM}$ patients determined the MTD as $140 \mathrm{mg} / \mathrm{m}^{2} /$ week dose and demonstrated an overall favorable safety profile [37]. Exciting single agent activity was observed in heavily pretreated MM patients, which warrant continued investigation of this novel agent in MM patients especially when used in combination with approved anti-MM agents/regimens such as lenalidomide and dexamethasone.

3.6. Targeting CD38 in Multiple Myeloma. The CD38 molecule is expressed on cell surfaces in a majority of lymphoid tumors, notably MM [38, 39]. However, early studies using anti-CD38 mAb with or without an immunotoxin (ricin) have not led to useful clinical applications $[4,40]$.

Recently, a human anti-CD38 IgG 1 HuMax-CD38 (Daratumumab) was raised after immunizing transgenic mice (HuMax-Mouse) possessing human, but not mouse, Ig genes. Preclinical studies indicated that HuMax-CD38 was effective in killing primary CD38+CD138+ patient MM cells and a range of MM/lymphoid cell lines by both ADCC and CDC [41]. In SCID mouse animal models, using sensitive bioluminescence imaging, treatment with $\mathrm{Hu}$.
Max-CD38 inhibited CD38+ tumor cell growth in both preventive and therapeutic settings. In addition, HuMaxCD38 inhibits the CD38 ADP-ribosyl cyclase activity in target cells, which may contribute to the effectiveness of HuMax-CD38 in killing both primary MM and plasma cell leukemia cells.

Similarly, MOR202 (MorphoSysAG), a fully human antiCD38 IgG $\mathrm{Ig}_{1} \mathrm{mAb}$ produced by a human combinatorial antibody library (HuCAL) platform, also efficiently triggers ADCC against CD38+ MM cell lines and patient MM cells in vitro as well as in vivo in a xenograft mouse model $[39,42]$. One practical problem in applying anti-CD38 therapy is the wide expression on lymphoid, myeloid, and epithelial cells, especially following cell activation. However, mAbs specifically blocking CD38 might still provide a new approach for interfering with deleterious growth circuits, therefore increasing the susceptibility of MM and leukemic cells to conventional chemotherapy.

3.7. Targeting HM1.24 on MM Cells. HM1.24 (CD317) was originally identified as a cell surface protein differentially overexpressed on MM cells [43] and later was found to be identical to bone stromal cell antigen 2 (BST-2). A role of HM1.24 in trafficking and signaling between the intracellular and cell surface of MM cells was suggested since it is one of the important activators of NF-kappaB pathway [44]. The humanized anti-HM1.24 mAb (IgG1/kappa, AHM, Chugai Pharmaceutical Co., Ltd.) is able to effectively induce ADCC against some human myeloma cells in the presence of human PBMCs as effectively as a chimeric anti-HM1.24 mAb [45]. Single intravenous injection of AHM significantly inhibited tumor growth in both orthotopic and ectopic human MM xenograft models [46]. Although limited, the only one phase I/II clinical study reported that a humanized anti-HM1.24 $\mathrm{mAb}$ did not cause any serious toxicity when administered to patients with relapsed or refractory MM [46].

Most recently, we characterized XmAb5592, a novel Fcengineered and humanized anti-HM1.24 mAb, and studied mechanisms of its anti-MM activity [47]. XmAb5592, with double amino acid substitution in Fc region of the wildtype IgG1, has approximately 40-fold and 10-fold increases in affinity for Fc gamma receptor III (FcRIIIa) and (FcRIIa), respectively, expressed on effector cells including NK cells. It triggers 10-100-fold higher ADCC against these MM cell lines than a native/non-Fc-engineered version (anti-HM1.24 IgG1) of the Ab. XmAb5592 also induced more potent anti-MM activity in murine subcutaneous xenograft murine models using RPMI 8226 cells. These results suggest that $\mathrm{XmAb5592}$ is a promising next generation immunotherapeutic for MM.

3.8. Targeting TRAIL Death Signaling Pathway. Two human agonistic mAbs directed against TRAILR1 (HGS-ETR1, TRM-1, Mapatumumab) and TRAILR2 (HGS-ETR2) killed $68 \%$ and $45 \%$ of MM cell lines, respectively, [48]. Only $18 \%$ of MM cell lines are resistant to either antibody. There is no correlation between TRAILR expression level and sensitivity to TRAIL-R1 or TRAIL-R2 triggering. Both the extrinsic 
(caspase 8, Bid) and the intrinsic (caspase 9) pathways are activated by anti-TRAIL mAbs. Mapatumumab is well tolerated in a phase I study in patients with advanced solid malignancies $(n=41)$ and 12 patients had stable disease for 1.9 to 29.4 months [49]. These studies encouraged clinical trials of anti-TRAILR1 mAb in MM. In addition, based on enhanced cytotoxicity when combining mapatumumab with bortezomib in preclinical experiments [50], a randomized phase II study was recently started comparing TRM-1 plus bortezomib (Velcade) versus bortezomib alone in patients with relapsed or refractory MM.

3.9. Targeting CD74 with Milatuzumab. CD74 is an integral membrane protein that functions as a MHC class II chaperone. Milatuzumab is a humanized anti-CD74 mAb constructed using the same human backbone as epratuzumab (anti-CD22), whose safety has been demonstrated in clinical trials of patients with B-cell malignancies and autoimmune disorders [51, 52]. MM cell lines express CD74 ( $60 \%$ of samples) and milatuzumab caused growth inhibition and induction of apoptosis in CD74-expressing MM cell lines when cross-linked with an anti-human immunoglobulin G secondary antibody [53]. Moreover milatuzumab demonstrated promising therapeutic activity in a CAG-SCID mouse model of disseminated disease for MM when used alone or in combination with doxorubicin, dexamethasone, bortezomib, or lenalidomide $[54,55]$. In a phase I trial, milatuzumab showed no severe adverse effects in patients with relapsed/refractory MM, and it stabilized the disease in some patients for up to 12 weeks [51]. Supporting the data in MM ongoing clinical trials testing different treatment schedules of milatuzumab in chronic lymphocytic leukemia, non-Hodgkin's lymphoma, and MM indicate that milatuzumab shows no severe adverse effects in humans.

\section{Antibodies Targeting MM Cells in the Bone Marrow Microenvironment}

MM cells are highly dependent on the BM microenvironment for growth and survival through interactions particularly with BM stromal cells (BMSCs) and osteoclasts, which secrete important MM growth factors and cytokines. Importantly, these factors/cytokines are further induced from BMSCs when MM cells adhere to BMSCs [10]. Thus, mAbs designed to block the binding of MM cell growth and survival factors to their cognate receptors have been under intensive development.

4.1. Blockage of IL-6 Binding to MM Cells. Early work in developing mAb-based immunotherapies for MM has been focused on the blockade of IL- 6 secretion from BM microenvironment because of its key role in promoting MM cell growth and survival. Initial studies of mouse mAb to IL6 (murine BE-4 and BE-8) demonstrated a transient tumor cytostasis and reduction in toxicities from IL-6 [56]. The potential of combination therapy, including BE-8 (250 mg), Dex (49 mg/day), and high-dose melphalan $\left(220 \mathrm{mg} / \mathrm{m}^{2}\right.$ (HDM220)), followed by autologous SCT was demonstrated for the treatment of 16 patients with advanced MM. Overall, 13 of 16 patients $(81.3 \%)$ exhibited a response, with a complete response (CR) seen in 6 patients $(37.5 \%)$ without any toxic or allergic reactions. However, the incidence of thrombocytopenia and neutropenia increased. Subsequent clinical trials of BE- 8 concluded that limitations of this regimen are first the amount of BE- 8 that can be injected due to its short half-life (3-4 days) and second, the continued production of IL-6 in vivo. Most recently, a high-affinity fully human version of BE-8, OP-R003-1 (or 1339, Azintrel), was selected through ActivMAb antibody discovery technology. Indeed, it enhanced cytotoxicity induced by dexamethasone, as well as bortezomib, lenalidomide, and perifosine, in a synergistic fashion [57]. Importantly, Azintrel also blocked bone turnover in SCID-hu mouse model of MM, providing an additional rationale for its use in MM.

Despite overcoming the safety concerns of human antimouse antibodies associated with murine anti-IL-6 mAb and a long half-life (17.8 days) in circulation, the chimeric mouse mAb to IL-6 CNTO 328 has been ineffective in producing a meaningful response in MM [58, 59]. Nevertheless, due to enhanced anti-MM activities of combined CNTO 328 and bortezomib/or dexamethasone in preclinical models, ongoing studies are investigating these regimens for their clinical value in treating MM $[60,61]$. Specifically, results of a small safety analysis $(n=21)$ done as a run-in to a larger ongoing Phase II trial showed promising preliminary efficacy of CNTO 328 in combination with bortezomib in relapsed/refractory MM. CNTO 328 is also being evaluated as part of a combination therapy for initial treatment of MM in a Phase II trial which compares the safety and effectiveness of CNTO 328 plus Velcade-melphalan-prednisone (VMP) with VMP alone.

\subsection{Targeting MM-Induced Bone Lesion}

4.2.1. Targeting RANK/RANKL/OPG Axis Using Denosumab for MM-Associated Bone Destruction. Receptor activator of nuclear factor-kappaB ligand (RANKL) is a cytokine member of the tumor necrosis factor family that is the principal mediator of osteoclastic bone resorption [62]. Osteoprotegerin (OPG), a natural soluble decoy receptor of RANKL, modulates the effect of RANKL and is able to prevent excessive bone resorption in the normal state. RANKL expression is elevated in patients with MM $[63,64]$. Denosumab (AMG 162, Amgen Inc., Thousand Oaks, CA) is an investigational fully human $\mathrm{mAb}$ with high affinity and specificity for RANKL that mimics the natural bone-protecting actions of OPG [65]. A phase 1 clinical trial in patients with MM $(n=$ $25)$ or breast cancer with bone metastases $(n=29)$ showed that following a single s.c. dose of denosumab $(0.1,0.3,1.0$, or $3.0 \mathrm{mg} / \mathrm{kg}$ ), levels of urinary and serum $\mathrm{N}$-telopeptide decreased within 1 day, and this decrease lasted through 84 days at the higher denosumab doses [66]. Mean half-lives of denosumab were 33.3 and 46.3 days for the two highest dosages. Larger trials are ongoing to investigate the effect of denosumab for the treatment of cancer-induced bone disease and other bone loss disorders [67]. 
4.2.2. Targeting the Wnt Inhibitor Dickkopf-1 (DKK-1). Dickkopf-1 (DKK1), a soluble inhibitor of wingless (Wnt) signaling secreted by MM cells contributes to osteolytic bone disease by inhibiting the differentiation of osteoblasts. The effect of anti-DKK1 mAb on bone metabolism and tumor growth in a SCID-rab system has been evaluated [68]. The implants of control animals showed signs of MM-induced resorption, whereas mice treated with antiDKK1 antibodies blunted resorption and improved the bone mineral density of the implants. Histologic examination revealed that myelomatous bones of anti-DKK1-treated mice had increased numbers of osteocalcin-expressing osteoblasts and reduced number of multinucleated TRAP-expressing osteoclasts. The bone anabolic effect of anti-DKK1 was associated with reduced MM burden $(P<.04)$. AntiDKK1 also significantly increased BMD of the implanted bone and murine femur in nonmyelomatous SCID-rab mice, suggesting that DKK1 is physiologically an important regulator of bone remodeling in adults. Anti-DKK1 agents including BHQ880 (Novartis) may therefore represent the next generation of therapeutic options for the enhancement of bone repair in some malignant and degenerative bone diseases including MM [69, 70]. Although BHQ880 had no direct effect on MM cell growth, BHQ880 increased osteoblast differentiation, neutralized the negative effect of MM cells on osteoblastogenesis, and reduced IL-6 secretion. Furthermore, in a SCID-hu murine model of human MM, BHQ880 treatment led to a significant increase in osteoblast number, serum human osteocalcin level, and trabecular bone. Preliminary results from a phase I/II trial in MM where BHQ880 was given IV for 28 days was well tolerated when given in combination with zoledronic acid.

4.2.3. Targeting the Activin Receptor Type IIA (ActRIIA). ACE-011, a novel bone anabolic agent currently in a Phase 2 clinical trial in MM, is a protein therapeutic based on the activin receptor IIA. In numerous preclinical models of bone loss, ACE-011 has demonstrated beneficial effects on both trabecular and cortical bone [71, 72]. ACE-011 increased bone mineral density, improved bone architecture, increased the mineral apposition and bone formation rates, and improved bone mechanical strength [73]. Results of the Phase 1 study in postmenopausal women demonstrated that a single dose of ACE-011 caused a rapid, sustained, dosedependent increase in serum levels of bone-specific alkaline phosphatase (BSAP), a marker of bone formation, while a marker of bone resorption, C-terminal type 1 collagen telopeptide (CTX), decreased. In MM an ongoing multicenter Phase 2 trial is conducted in Russian patients which are treated with melphalan, prednisone, and thalidomide and randomized to receive either monthly doses of ACE011 or placebo for up to three months. Preliminary results show clinical significant increases in biomarkers of bone formation, improvement in skeletal metastases, decreases in bone pain as well as antitumor activity [54]. In summary, these data indicate that ACE-011 is well tolerated and has significant hematologic activity in MM patients receiving myelosuppressive chemotherapy.
Moreover, ACE-011 has potential as a novel therapy for chemotherapy-induced anemia and may be an effective alternative to erythropoietin- (EPO-) based treatments.

\subsection{Targeting Angiogenesis by VEGF Inhibitor Bevacizumab} (Avastin). Vascular endothelial factor (VEGF) is important for the formation of new blood vessels and plays a key role not only in solid tumors but also in hematologic malignancies, including MM [74]. Bevacizumab targets and blocks VEGF and VEGF's binding to its receptor on the vascular endothelium [75]. Anti-VEGF Abs were active alone, and in combination with radiation in earlier preclinical studies [75, 76]. It is currently being studied clinically in many solid and blood tumors including primary systemic amyloidosis and MM [77, 78]. NCI's Cancer Therapy Evaluation Program is sponsoring a phase II study of bevacizumab plus thalidomide in $\mathrm{MM}$ [78].

\subsection{Targeting BAFF/ARPIL Growth and Survival Pathway} by Atacicept (TACI-Ig) or BAFF Inhibitor. Recently, B-cell activating factor of the tumor necrosis factor (TNF) family (BAFF; also known as B lymphocyte stimulator, BLyS) and a proliferation inducing ligand (APRIL), were identified as new survival factors for MM [79-81]. In addition to BMSCs, osteoclasts produce these factors to support MM cells in the BM microenvironment $[81,82]$. Their cognate receptors are $\mathrm{BAFF}-\mathrm{R} / \mathrm{BR} 3$, transmembrane activator and calcium modulator (TACI), and B-cell maturation antigen (BCMA) with heterogeneous expression among patient MM cells. Specifically, RNA expression of BCMA and TACI is approximately $>30$-fold and $>10$-fold higher, respectively, than that of BR3 [81]. BR3 specifically binds BAFF but not APRIL, and has very limited expression in mature Bcells plasma cells [83]. In fact, BCMA expression is only acquired in mature B cells and accompanied by loss of BAFF$\mathrm{R}$ expression [83], suggesting a key role of BCMA in plasma cell survival. These studies provide clinical rationale to target BAFF/APRIL survival pathway in MM.

Atacicept (TACI-Ig, ZymoGenetics; Serono) acts as a decoy receptor by binding to and neutralizing soluble BAFF and APRIL, and preventing these ligands from binding to their cognate receptors on B-cell tumors, thereby enhancing cytotoxicity. An open-label, dose-escalation Phase I/II study enrolled 16 patients with refractory or relapsed MM ( $n=$ 12 ) or active, progressive Waldenstrom's Macroglobulinemia $(n=4)[84]$. Atacicept was well tolerated and showed clinical and biological activity consistent with its mechanism of action. TACI was expressed heterogeneously among patient MM cells, which may explain promising results for the treatment of TACI ${ }^{\text {high }} \mathrm{MM}$ cells in a trial for atacicept [84, 85].

In addition, the in vivo antitumor activity of neutralizing anti-BAFF mAb in SCID-hu model of human MM provide the preclinical rationale for its evaluation in the treatment of MM [86]. Moreover, since all MM cell lines and patient MM cells express BCMA, BCMA might be a promising target for monoclonal antibody development against MM. Importantly, MM cells in remission postallogeneic transplant 
due to graft-versus-tumor response have donor derived antiBCMA Abs that are tumor lytic in vivo [87]. Thus, BCMA is a target of donor B-cell immunity in patients with myeloma who respond to donor lymphocyte infusion (DLI). Antibody responses to cell-surface BCMA may contribute directly to tumor rejection in vivo. Indeed, BCMA antibodies show cytotoxic activity both as naked IgG and as drug conjugates, which warrant further evaluation as therapeutic candidates for plasma cell malignancies [88].

4.5. Other Potential Targets. Additional mAbs are directed against a variety of further MM cell targets including HLADR by 1D09C3 [89], HLA-class I by 2D7-DB [90], kininogen by $\mathrm{C} 11 \mathrm{C} 1$ [91], and polyclonal rabbit antithymocyte globulin (rATG) [92].

Finally, since NK cells play a critical role in ADCC to lyse tumor target cells via therapeutic monoclonal antibodies and inhibitory-cell killer immunoglobulin-like receptors (KIRs) negatively regulate natural killer (NK) cell-mediated killing of HLA class I-expressing tumors, mAbs targeting KIR might prevent their inhibitory signaling leading to enhanced ADCC. A novel fully human anti-KIR blocking mAb, 17F9 (or IPH 2101), antagonizes inhibitory KIR signaling, activates NK cells and augments natural killer-mediated killing of tumor cells $[93,94]$. Importantly, 1-7F9 enhances patient NK cell cytotoxicity against autologous MM tumor cells in vitro and appears safe in an ongoing phase I clinical trial [95]. A multicenter, open label Phase IIa clinical trial (trial IPH 2101-201, in France) has started to evaluate IPH 2101 as a single agent in patients with stable measurable MM after induction therapy. Another phase II clinical trial to assess the potential of lenalidomide combined with 1-7F9 will be initiated in patients with MM.

\section{Conclusion}

For the past decade, more than a dozen of therapeutic mAbs have either entered clinical trials or in clinical development in MM. However, mAbs targeting myeloma cells have not yet been included as part of standard myeloma therapy. Although the ability to create essentially human antibody structures has reduced the likelihood of hostprotective immune responses that otherwise limit the utility of therapy, majority of MM patients are immunosuppressive. The immediate goal would be testing next generations of genetically Fc-engineered mAbs that not only binds to target MM antigens with high affinity but also have superior interaction ( $>1 \mathrm{log}$ ) with host immune effectors. A better understanding of the immune defects that prevent MM patients from mounting a strong response against their tumor cells should also improve establishment of effective mAb-based immunotherapy strategies for MM. We expect that, the use of potentially targeted therapies by mAbs, such as Fc-engineered naked or immunoconjugate or bispecific would soon claim defined therapeutic roles in patients with MM. The favorable toxicity profile of tumor-targeted therapy by mAbs, unlike other forms of therapy, may allow the maintenance of quality of life, while efficiently attack the tumors.

\section{References}

[1] S. P. Treon, Y. Shima, M. L. Grossbard et al., "Treatment of multiple myeloma by antibody mediated immunotherapy and induction of myeloma selective antigens," Annals of Oncology, vol. 11, no. 1, pp. S107-S111, 2000.

[2] C. Gemmel, F. W. Cremer, M. Weis et al., "Anti-CD20 antibody as consolidation therapy in a patient with primary plasma cell leukemia after high-dose therapy and autologous stem cell transplantation," Annals of Hematology, vol. 81, no. 2, pp. 119123, 2002.

[3] P. Musto, A. M. Carella Jr., M. M. Greco et al., "Short progression-free survival in myeloma patients receiving rituximab as maintenance therapy after autologous transplantation," British Journal of Haematology, vol. 123, no. 4, pp. 746747, 2003.

[4] J. H. Ellis, K. A. Barber, A. Tutt et al., "Engineered antiCD38 monoclonal antibodies for immunotherapy of multiple myeloma," Journal of Immunology, vol. 155, no. 2, pp. 925-937, 1995.

[5] N. Zojer, K. Kirchbacher, M. Vesely, W. Hübl, and H. Ludwig, "Rituximab treatment provides no clinical benefit in patients with pretreated advanced multiple myeloma," Leukemia and Lymphoma, vol. 47, no. 6, pp. 1103-1109, 2006.

[6] N. Robillard, H. Avet-Loiseau, R. Garand et al., "CD20 is associated with a small mature plasma cell morphology and $\mathrm{t}(11 ; 14)$ in multiple myeloma," Blood, vol. 102, no. 3, pp. 1070-1071, 2003.

[7] A. Gozzetti, A. Fabbri, S. Lazzi, M. Bocchia, and F. Lauria, "Reply to Rituximab activity in CD20 positive multiple myeloma," Leukemia, vol. 21, no. 8, pp. 1842-1843, 2007.

[8] S. Hofer, S. Hunziker, S. Dirnhofer, and C. Ludwig, "Rituximab effective in a patient with refractory autoimmune haemolytic anaemia and CD20-negative multiple myeloma," British Journal of Haematology, vol. 122, no. 4, pp. 690-691, 2003.

[9] C. A. Huff and W. Matsui, "Multiple myeloma cancer stem cells," Journal of Clinical Oncology, vol. 26, no. 17, pp. 28952900, 2008.

[10] T. Hideshima, C. Mitsiades, G. Tonon, P. G. Richardson, and K. C. Anderson, "Understanding multiple myeloma pathogenesis in the bone marrow to identify new therapeutic targets," Nature Reviews Cancer, vol. 7, no. 8, pp. 585-598, 2007.

[11] M. Trikha, R. Corringham, B. Klein, and J. F. Rossi, “Targeted anti-interleukin-6 monoclonal antibody therapy for cancer: a review of the rationale and clinical evidence," Clinical Cancer Research, vol. 9, no. 13, pp. 4653-4665, 2003.

[12] D. Honemann, M. Chatterjee, R. Savino et al., "The IL-6 receptor antagonist SANT-7 overcomes bone marrow stromal cell-mediated drug resistance of multiple myeloma cells," International Journal of Cancer, vol. 93, no. 5, pp. 674-680, 2001.

[13] P. Tassone, S. Forciniti, E. Galea et al., "Synergistic induction of growth arrest and apoptosis of human myeloma cells by the IL-6 super-antagonist Sant7 and Dexamethasone," Cell Death and Differentiation, vol. 7, no. 3, pp. 327-328, 2000.

[14] P. Tassone, E. Galea, S. Forciniti, P. Tagliaferri, and S. Venuta, "The IL-6 receptor super-antagonist Sant7 enhances antiproliferative and apoptotic effects induced by dexamethasone and zoledronic acid on multiple myeloma cells," International Journal of Oncology, vol. 21, no. 4, pp. 867-873, 2002. 
[15] S. L. Plushner, "Tocilizumab: an interleukin-6 receptor inhibitor for the treatment of rheumatoid arthritis," Annals of Pharmacotherapy, vol. 42, no. 11, pp. 1660-1668, 2008.

[16] J. Kanda, H. Kawabata, Y. Yamaji et al., "Reversible cardiomyopathy associated with multicentric Castleman diseases: successful treatment with tocilizumab, an anti-interleukin 6 receptor antibody," International Journal of Hematology, vol. 85, no. 3, pp. 207-211, 2007.

[17] N. Nishimoto, "Clinical studies in patients with Castleman's disease, Crohn's disease, and rheumatoid arthritis in Japan," Clinical Reviews in Allergy and Immunology, vol. 28, no. 3, pp. 221-229, 2005.

[18] P. Woo, N. Wilkinson, A. M. Prieur et al., "Open label phase II trial of single, ascending doses of MRA in Caucasian children with severe systemic juvenile idiopathic arthritis: proof of principle of the efficacy of IL-6 receptor blockade in this type of arthritis and demonstration of prolonged clinical improvement," Arthritis Research \& Therapy, vol. 7, no. 6, pp. R1281-R1288, 2005.

[19] N. Yoshio-Hoshino, Y. Adachi, C. Aoki, A. Pereboev, D. T. Curiel, and N. Nishimoto, "Establishment of a new interleukin-6 (IL-6) receptor inhibitor applicable to the gene therapy for IL-6-dependent tumor," Cancer Research, vol. 67, no. 3, pp. 871-875, 2007.

[20] Y. T. Tai, L. P. Catley, C. S. Mitsiades et al., "Mechanisms by which SGN-40, a humanized anti-CD40 antibody, induces cytotoxicity in human multiple myeloma cells: clinical implications," Cancer Research, vol. 64, no. 8, pp. 2846-2852, 2004.

[21] Y. T. Tai, X. Li, X. Tong et al., "Human anti-CD40 antagonist antibody triggers significant antitumor activity against human multiple myeloma," Cancer Research, vol. 65, no. 13, pp. 58985906, 2005.

[22] C. L. Law, K. A. Gordon, J. Collier et al., "Preclinical antilymphoma activity of a humanized anti-CD40 monoclonal antibody, SGN-40," Cancer Research, vol. 65, no. 18, pp. 83318338, 2005.

[23] L. Long, X. Tong, M. Patawaran et al., "Antagonist anti-CD40 antibody CHIR-12.12 causes tumor regression and prolongs survival in multiple myeloma xenograft models," IMF Oral Presentation and Abstract, no. 3, 2005.

[24] W. Bensinger, S. Jagannath, P. S. Becker et al., "A phase 1 dose escalation study of a fully human, antagonist anti-CD40 antibody, HCD 122 (formerly CHIR-12.12), in patients with relapsed and refractory multiple myeloma," Blood, vol. 108, 2006, abstract no. 3675 .

[25] M. A. Hussein, J. R. Berenson, R. Niesvizky et al., "Results of a phase I trial of SGN-40 (anti-huCD40 mAb) in patients with relapsed multiple myeloma," Blood, vol. 108, article 3576, 2006.

[26] S. Khubchandani, M. S. Czuczman, and F. J. HernandezIlizaliturri, "Dacetuzumab, a humanized $\mathrm{mAb}$ against CD40 for the treatment of hematological malignancies," Current Opinion in Investigational Drugs, vol. 10, no. 6, pp. 579-587, 2009.

[27] R. Advani, A. Forero-Torres, R. R. Furman et al., "Phase I study of the humanized anti-CD40 monoclonal antibody dacetuzumab in refractory or recurrent non-Hodgkin's lymphoma," Journal of Clinical Oncology, vol. 27, no. 26, pp. 43714377, 2009.

[28] Y. T. Tai, X. F. Li, L. Catley et al., "Immunomodulatory drug lenalidomide (CC-5013, IMiD3) augments anti-CD40 SGN40-induced cytotoxicity in human multiple myeloma: clinical implications," Cancer Research, vol. 65, no. 24, pp. 1171211720, 2005.
[29] Y. T. Tai, M. Dillon, W. Song et al., "Anti-CSl humanized monoclonal antibody HuLuc63 inhibits myeloma cell adhesion and induces antibody-dependent cellular cytotoxicity in the bone marrow milieu," Blood, vol. 112, no. 4, pp. 1329-1337, 2008.

[30] E. D. Hsi, R. Steinle, B. Balasa et al., "CS1, a potential new therapeutic antibody target for the treatment of multiple myeloma," Clinical Cancer Research, vol. 14, no. 9, pp. 27752784, 2008.

[31] Y. T. Tai, E. Soydan, W. Song et al., "CS1 promotes multiple myeloma cell adhesion, clonogenic growth, and tumorigenicity via c-maf-mediated interactions with bone marrow stromal cells," Blood, vol. 113, no. 18, pp. 4309-4318, 2009.

[32] F. van Rhee, S. M. Szmania, M. Dillon et al., "Combinatorial efficacy of anti-CS1 monoclonal antibody elotuzumab (HuLuc63) and bortezomib against multiple myeloma," Molecular Cancer Therapeutics, vol. 8, no. 9, pp. 2616-2624, 2009.

[33] W. Bensinger, J. Zonder, S. Singhal et al., "Phase I trial of HuLuc63 in multiple myeloma," Blood, vol. 110, 2007.

[34] A. J. Jakubowiak, W. Bensinger, D. Siegel et al., "Phase 1/2 study of elotuzumab in combination with bortezomib in patients with multiple myeloma with one to three prior therapies: interim results," Blood, vol. 114, article 3876, 2009.

[35] S. Lonial, R. Vij, J.-L. Harousseau et al., "Phase 1/2 study of elotuzumab in combination with lenalidomide and low dose dexamethasone in relapsed or refractory multiple myeloma: interim results," Blood, vol. 114, article 432, 2009.

[36] P. Tassone, A. Gozzini, V. Goldmacher et al., "In vitro and in vivo activity of the maytansinoid immunoconjugate huN901-N2' -deacetyl-N2' -(3-mercapto-1-oxopropyl)maytansine against CD56+ multiple myeloma cells," Cancer Research, vol. 64, no. 13, pp. 4629-4636, 2004.

[37] A. Chanan-Khan, J. Wolf, M. Gharibo et al., "Phase I study of IMGN901, used as monotherapy, in patients with heavily pre-treated CD56-positive multiple myeloma-a preliminary safety and efficacy analysis," Blood, vol. 114, article 2883, 2009.

[38] F. K. Stevenson, A. J. Bell, R. Cusack et al., "Preliminary studies for an immunotherapeutic approach to the treatment of human myeloma using chimeric anti-CD38 antibody," Blood, vol. 77, no. 5, pp. 1071-1079, 1991.

[39] G. T. Stevenson, "CD38 as a therapeutic target," Molecular Medicine, vol. 12, no. 11-12, pp. 345-346, 2006.

[40] V. S. Goldmacher, L. A. Bourret, B. A. Levine et al., "AntiCD38-blocked ricin: an immunotoxin for the treatment of multiple myeloma," Blood, vol. 84, no. 9, pp. 3017-3025, 1994.

[41] Y. T. Tai, M. de Weers, X. Li et al., "Daratumumab, a novel potent human anti-CD38 monoclonal antibody, induces significant killing of human multiple myeloma cells," Therapeutic Implication, vol. 114, article 608, 2009.

[42] M. Tesar, "Fully human antibody MOR202 against CD38 for the treatment of multiple myeloma and other blood-borne malignancies," Journal of Clinical Oncology, vol. 25, article 8106, 2007.

[43] S. Ozaki, M. Kosaka, S. Wakatsuki, M. Abe, Y. Koishihara, and T. Matsumoto, "Immunotherapy of multiple myeloma with a monoclonal antibody directed against a plasma cell-specific antigen, HM1.24," Blood, vol. 90, no. 8, pp. 3179-3186, 1997.

[44] A. Matsuda, Y. Suzuki, G. Honda et al., "Large-scale identification and characterization of human genes that activate NF- $\kappa \mathrm{B}$ and MAPK signaling pathways," Oncogene, vol. 22, no. 21, pp. 3307-3318, 2003. 
[45] S. Ozaki, M. Kosaka, Y. Wakahara et al., "Humanized antiHM1.24 antibody mediates myeloma cell cytotoxicity that is enhanced by cytokine stimulation of effector cells," Blood, vol. 93, no. 11, pp. 3922-3930, 1999.

[46] S. Kawai, Y. Yoshimura, S. I. Iida et al., "Antitumor activity of humanized monoclonal antibody against HM1.24 antigen in human myeloma xenograft models," Oncology Reports, vol. 15, no. 2, pp. 361-367, 2006.

[47] Y. T. Tai, U. Muchhal, X. Li et al., "XmAb®5592 Fc-engineered humanized anti-HM1.24 monoclonal antibody has potent in vitro and in vivo efficacy against multiple myeloma," Blood, vol. 114, article 609, 2009.

[48] E. Menoret, P. Gomez-Bougie, A. Geffroy-Luseau et al., "Mcl-1L cleavage is involved in TRAIL-R1- and TRAIL-R2mediated apoptosis induced by HGS-ETR1 and HGS-ETR2 human mAbs in myeloma cells," Blood, vol. 108, no. 4, pp. 1346-1352, 2006.

[49] S. J. Hotte, H. W. Hirte, E. X. Chen et al., "A phase 1 study of mapatumumab (fully human monoclonal antibody to TRAILR1) in patients with advanced solid malignancies," Clinical Cancer Research, vol. 14, no. 11, pp. 3450-3455, 2008.

[50] M. R. Smith, F. Jin, and I. Joshi, "Bortezomib sensitizes nonHodgkin's lymphoma cells to apoptosis induced by antibodies to tumor necrosis factor-related apoptosis-inducing ligand (TRAIL) receptors TRAIL-R1 and TRAIL-R2," Clinical Cancer Research, vol. 13, no. 18, part 2, pp. 5528s-5534s, 2007.

[51] Z. Berkova, R. H. Tao, and F. Samaniego, "Milatuzumab-a promising new immunotherapeutic agent," Expert Opinion on Investigational Drugs, vol. 19, no. 1, pp. 141-149, 2010.

[52] R. Stein, M. J. Mattes, T. M. Cardillo et al., "CD74: a new candidate target for the immunotherapy of B-cell neoplasms," Clinical Cancer Research, vol. 13, no. 18, part 2, pp. 5556s5563s, 2007.

[53] J. D. Burton, S. Ely, P. K. Reddy et al., "CD74 is expressed by multiple myeloma and is a promising target for therapy," Clinical Cancer Research, vol. 10, no. 19, pp. 6606-6611, 2004.

[54] K. M. Abdulkadyrov, G. N. Salogub, N. K. Khuazheva et al., "ACE-011, a soluble activin receptor type Iia IgG-Fc fusion protein, increases hemoglobin $(\mathrm{Hb})$ and improves bone lesions in multiple myeloma patients receiving myelosuppressive chemotherapy: preliminary analysis," Blood, vol. 114, article 749, 2009.

[55] R. Stein, M. R. Smith, S. Chen, M. Zalath, and D. M. Goldenberg, "Combining milatuzumab with bortezomib, doxorubicin, or dexamethasone improves responses in multiple myeloma cell lines," Clinical Cancer Research, vol. 15, no. 8, pp. 2808-2817, 2009.

[56] P. Moreau, J. L. Harousseau, J. Wijdenes, N. Morineau, N. Milpied, and R. Bataille, "A combination of anti-interleukin 6 murine monoclonal antibody with dexamethasone and high-dose melphalan induces high complete response rates in advanced multiple myeloma," British Journal of Haematology, vol. 109, no. 3, pp. 661-664, 2000.

[57] M. Fulciniti, T. Hideshima, C. Vermot-Desroches et al., "A high-affinity fully human anti-IL-6 mAb, 1339, for the treatment of multiple myeloma," Clinical Cancer Research, vol. 15, no. 23, pp. 7144-7152, 2009.

[58] H. C. T. van Zaanen, H. M. Lokhorst, L. A. Aarden, H. J. A. M. Rensink, S. O. Warnaar, and M. H. J. van Oers, "Blocking interleukin-6 activity with chimeric anti-IL6 monoclonal antibodies in multiple myeloma: effects on soluble IL6 receptor and soluble gp 130," Leukemia and Lymphoma, vol. 31, no. 5-6, pp. 551-558, 1998.
[59] H. C. T. van Zaanen, H. M. Lokhorst, L. A. Aarden et al., "Chimaeric anti-interleukin 6 monoclonal antibodies in the treatment of advanced multiple myeloma: a phase I doseescalating study," British Journal of Haematology, vol. 102, no. 3, pp. 783-790, 1998.

[60] P. M. Voorhees, Q. Chen, D. J. Kuhn et al., "Inhibition of interleukin-6 signaling with CNTO 328 enhances the activity of bortezomib in preclinical models of multiple myeloma," Clinical Cancer Research, vol. 13, no. 21, pp. 6469-6478, 2007.

[61] P. M. Voorhees, Q. Chen, G. W. Small et al., "Targeted inhibition of interleukin-6 with CNTO 328 sensitizes preclinical models of multiple myeloma to dexamethasonemediated cell death," British Journal of Haematology, vol. 145, no. 4, pp. 481-490, 2009.

[62] E. M. Lewiecki, "RANK ligand inhibition with denosumab for the management of osteoporosis," Expert Opinion on Biological Therapy, vol. 6, no. 10, pp. 1041-1050, 2006.

[63] E. Terpos, R. Szydlo, J. F. Apperley et al., "Soluble receptor activator of nuclear factor $\kappa \mathrm{B}$ ligand-osteoprotegerin ratio predicts survival in multiple myeloma: proposal for a novel prognostic index," Blood, vol. 102, no. 3, pp. 1064-1069, 2003.

[64] N. Giuliani, R. Bataille, C. Mancini, M. Lazzaretti, and S. Barillé, "Myeloma cells induce imbalance in the osteoprotegerin/osteoprotegerin ligand system in the human bone marrow environment," Blood, vol. 98, no. 13, pp. 3527-3533, 2001.

[65] J. S. Burkiewicz, S. L. Scarpace, and S. P. Bruce, "Denosumab in osteoporosis and oncology," Annals of Pharmacotherapy, vol. 43, no. 9, pp. 1445-1455, 2009.

[66] J. J. Body, T. Facon, R. E. Coleman et al., "A study of the biological receptor activator of nuclear factor- $\kappa \mathrm{B}$ ligand inhibitor, denosumab, in patients with multiple myeloma or bone metastases from breast cancer," Clinical Cancer Research, vol. 12 , no. 4 , pp. 1221-1228, 2006.

[67] D. Santini, M. E. Fratto, B. Vincenzi et al., "Denosumab: the era of targeted therapies in bone metastatic diseases," Current Cancer Drug Targets, vol. 9, no. 7, pp. 834-842, 2009.

[68] S. Yaccoby, W. Ling, F. Zhan, R. Walker, B. Barlogie, and J. D. Shaughnessy, "Antibody-based inhibition of DKK1 suppresses tumor-induced bone resorption and multiple myeloma growth in vivo," Blood, vol. 109, no. 5, pp. 21062111, 2007.

[69] D. J. Heath, A. D. Chantry, C. H. Buckle et al., "Inhibiting dickkopf-1 (Dkkl) removes suppression of bone formation and prevents the development of osteolytic bone disease in multiple myeloma," Journal of Bone and Mineral Research, vol. 24, no. 3, pp. 425-436, 2009.

[70] M. Fulciniti, P. Tassone, T. Hideshima et al., "Anti-DKK1 $\mathrm{mAb}(\mathrm{BHQ} 880)$ as a potential therapeutic agent for multiple myeloma," Blood, vol. 114, no. 2, pp. 371-379, 2009.

[71] S. Lotinun, R. S. Pearsall, M. V. Davies et al., "A soluble activin receptor Type IIA fusion protein (ACE-011) increases bone mass via a dual anabolic-antiresorptive effect in Cynomolgus monkeys," Bone, vol. 46, no. 4, pp. 1082-1088, 2010.

[72] S. Vallet, S. Mukherjee, N. Vaghela et al., "Restoration of bone balance via activin a inhibition results in anti-myeloma activity," Blood, vol. 114, article 645, 2008.

[73] J. Ruckle, M. Jacobs, W. Kramer et al., "Single-dose, randomized, double-blind, placebo-controlled study of ACE-011 (ActRIIA-IgGl) in postmenopausal women," Journal of Bone and Mineral Research, vol. 24, no. 4, pp. 744-752, 2009.

[74] K. Podar and K. C. Anderson, "Inhibition of VEGF signaling pathways in multiple myeloma and other malignancies," Cell Cycle, vol. 6, no. 5, pp. 538-542, 2007. 
[75] N. Ferrara, K. J. Hillan, and W. Novotny, "Bevacizumab (Avastin), a humanized anti-VEGF monoclonal antibody for cancer therapy," Biochemical and Biophysical Research Communications, vol. 333, no. 2, pp. 328-335, 2005.

[76] D. H. Gorski, M. A. Beckett, N. T. Jaskowiak et al., "Blockade of the vascular endothelial growth factor stress response increases the antitumor effects of ionizing radiation," Cancer Research, vol. 59, no. 14, pp. 3374-3378, 1999.

[77] R. J. Hoyer, N. Leung, T. E. Witzig, and M. Q. Lacy, "Treatment of diuretic refractory pleural effusions with bevacizumab in four patients with primary systemic amyloidosis," American Journal of Hematology, vol. 82, no. 5, pp. 409-413, 2007.

[78] B. Goldman, "For investigational targeted drugs, combination trials pose challenges," Journal of the National Cancer Institute, vol. 95, no. 23, pp. 1744-1746, 2003.

[79] A. J. Novak, J. R. Darce, B. K. Arendt et al., "Expression of BCMA, TACI, and BAFF-R in multiple myeloma: a mechanism for growth and survival," Blood, vol. 103, no. 2, pp. 689-694, 2004.

[80] J. Moreaux, E. Legouffe, E. Jourdan et al., "BAFF and APRIL protect myeloma cells from apoptosis induced by interleukin 6 deprivation and dexamethasone," Blood, vol. 103, no. 8, pp. 3148-3157, 2004.

[81] Y. T. Tai, X. F. Li, I. Breitkreutz et al., "Role of B-cell-activating factor in adhesion and growth of human multiple myeloma cells in the bone marrow microenvironment," Cancer Research, vol. 66, no. 13, pp. 6675-6682, 2006.

[82] J. Moreaux, F. W. Cremer, T. Reme et al., "The level of TACI gene expression in myeloma cells is associated with a signature of microenvironment dependence versus a plasmablastic signature," Blood, vol. 106, no. 3, pp. 1021-1030, 2005.

[83] J. R. Darce, B. K. Arendt, X. Wu, and D. F. Jelinek, "Regulated expression of BAFF-binding receptors during human B cell differentiation," Journal of Immunology, vol. 179, no. 11, pp. 7276-7286, 2007.

[84] J. F. Rossi, J. Moreaux, D. Hose et al., "Atacicept in relapsed/refractory multiple myeloma or active Waldenstrom's macroglobulinemia: a phase I study," British Journal of Cancer, vol. 101, no. 7, pp. 1051-1058, 2009.

[85] S. Yaccoby, A. Pennisi, X. Li et al., "Atacicept (TACI-Ig) inhibits growth of TACI primary myeloma cells in SCID-hu mice and in coculture with osteoclasts," Leukemia, vol. 22, no. 2, pp. 406-413, 2008.

[86] P. Neri, S. Kumar, M. T. Fulciniti et al., "Neutralizing Bcell-activating factor antibody improves survival and inhibits osteoclastogenesis in a severe combined immunodeficient human multiple myeloma model," Clinical Cancer Research, vol. 13, no. 19, pp. 5903-5909, 2007.

[87] R. Bellucci, E. P. Alyea, S. Chiaretti et al., "Graft-versus-tumor response in patients with multiple myeloma is associated with antibody response to BCMA, a plasma-cell membrane receptor," Blood, vol. 105, no. 10, pp. 3945-3950, 2005.

[88] M. C. Ryan, M. Hering, D. Peckham et al., "Antibody targeting of B-cell maturation antigen on malignant plasma cells," Molecular Cancer Therapeutics, vol. 6, no. 11, pp. 3009-3018, 2007.

[89] C. Carlo-Stella, A. Guidetti, M. Di Nicola et al., "IFN- $\gamma$ enhances the antimyeloma activity of the fully human antihuman leukocyte antigen-DR monoclonal antibody 1D09C3," Cancer Research, vol. 67, no. 7, pp. 3269-3275, 2007.

[90] E. Sekimoto, S. Ozaki, T. Ohshima et al., "A single-chain Fv diabody against human leukocyte antigen-a molecules specifically induces myeloma cell death in the bone marrow environment," Cancer Research, vol. 67, no. 3, pp. 1184-1192, 2007.

[91] I. M. Sainz, I. Isordia-Salas, R. G. Espinola, W. K. Long, R. A. Pixley, and R. W. Colman, "Multiple myeloma in a murine syngeneic model: modulation of growth and angiogenesis by a monoclonal antibody to kininogen," Cancer Immunology, Immunotherapy, vol. 55, no. 7, pp. 797-807, 2006.

[92] M. S. Zand, T. Vo, T. Pellegrin et al., "Apoptosis and complement-mediated lysis of myeloma cells by polyclonal rabbit antithymocyte globulin," Blood, vol. 107, no. 7, pp. 2895-2903, 2006.

[93] S. E. Johansson, B. Hejdeman, J. Hinkula et al., "NK cell activation by KIR-binding antibody 1-7F9 and response to HIV-infected autologous cells in viremic and controller HIVinfected patients," Clinical Immunology, vol. 134, no. 2, pp. 158-168, 2010.

[94] F. Romagne, P. Andre, P. Spee et al., "Preclinical characterization of 1-7F9, a novel human anti-KIR receptor therapeutic antibody that augments natural killer-mediated killing of tumor cells," Blood, vol. 114, no. 13, pp. 2667-2677, 2009.

[95] D. M. Benson, F. Romagne, P. Squiban et al., "Novel monoclonal antibody that enhances natural killer (NK) cell cytotoxicity against multiple myeloma (MM): preclinical data and interim phase I clinical trial results," Journal of Clinical Oncology, vol. 27, no. 15s, 2009, abstract no. 3032. 


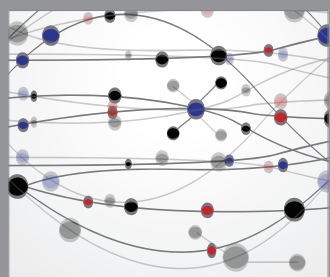

The Scientific World Journal
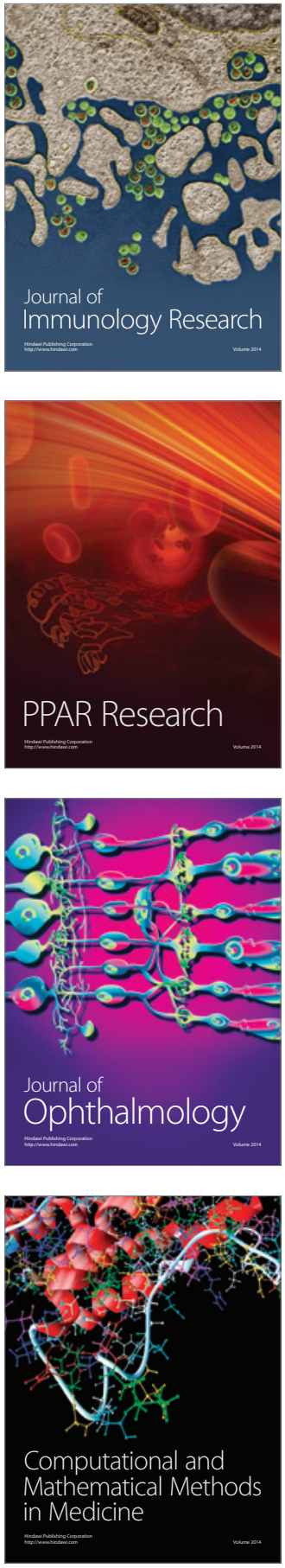

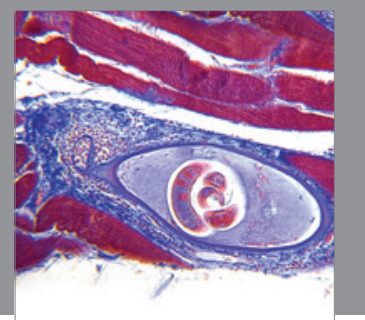

Gastroenterology

Research and Practice
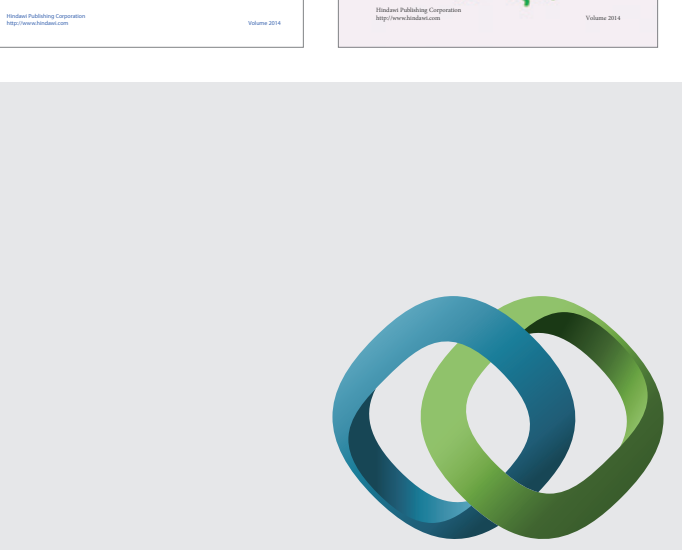

\section{Hindawi}

Submit your manuscripts at

http://www.hindawi.com
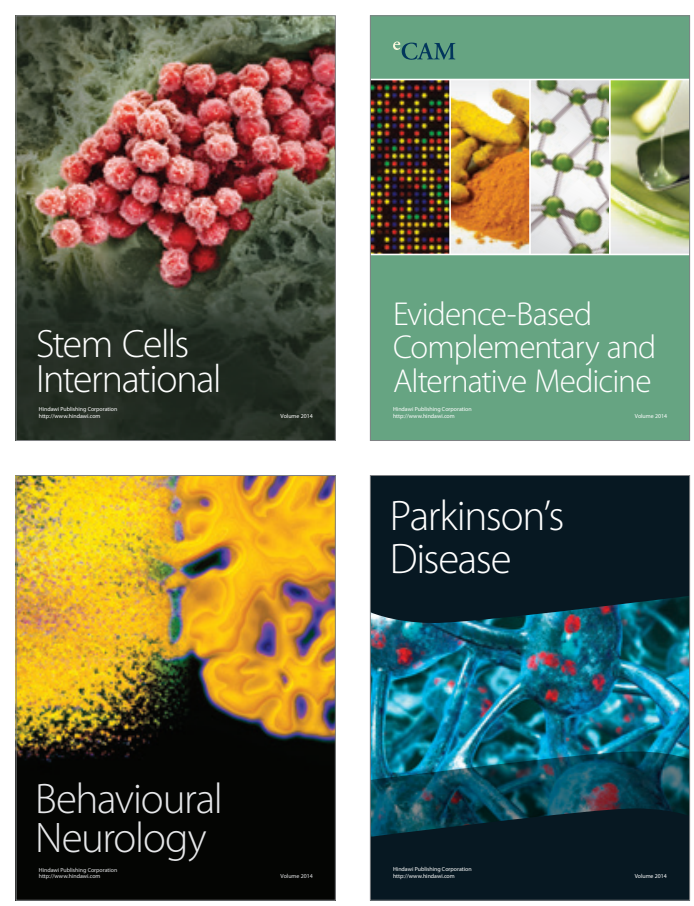

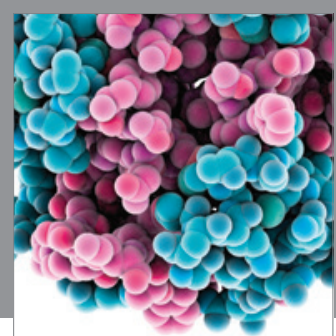

Journal of
Diabetes Research

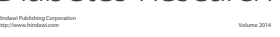

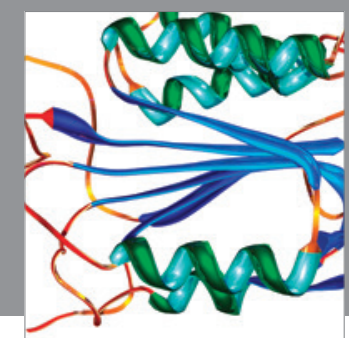

Disease Markers
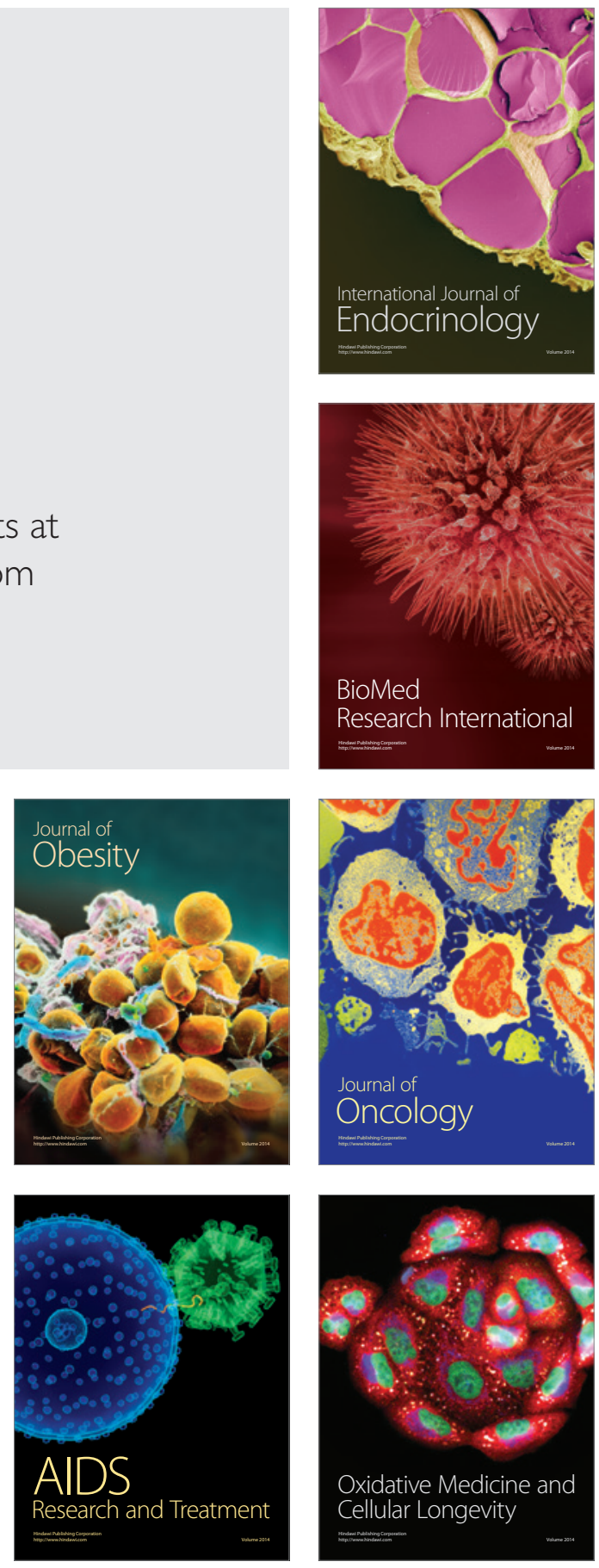